\title{
The methodological approach to analyzing the food security sustainability in the context of import substitution
}

\author{
Elena Antamoshkina ${ }^{1, *}$, and Aleksey Rogachev ${ }^{1,2}$ \\ ${ }^{1}$ Volgograd State Agricultural University, Universitetskiy Avenue, 26, 400002 Volgograd, Russia \\ ${ }^{2}$ Volgograd State Technical University, Lenina Avenue, 28, 400005 Volgograd, Russia
}

\begin{abstract}
The food security of the state must be sustainable. This actualizes the problem of assessing food security and its sustainability. To assess the sustainability of food security, a methodology based on a dynamic, multivariate assessment model is recommended. The proposed model allows considering the influence of systematized factors that form food security in production (P), distribution (D), consumption (C), and import substitution of food products (I). A comprehensive indicator for assessing the sustainability of food security has been developed - the food security sustainability index $\left(I_{F S}\right)$, which sets a functional relationship between the influence of the analyzed factors and the achieved level of food security. The theoretical significance of the study lies in the development of a new original methodology and methodological toolkit to assess the provision of the population with food and the sustainability of food security.
\end{abstract}

\section{Introduction}

The problem of food security is traditionally most acute in the developing countries of the world. While food security continues to improve in developed countries, it is gradually declining in developing ones. The developing countries of the world are severely food insecure, and their populations often suffer from poverty and malnutrition. According to FAO, countries in several developing regions are among the countries with the lowest indicators of food security, bordering on extremely low levels, malnutrition and hunger, persistent food shortages: countries in sub-Saharan Africa (Central African Republic, Kenya, Swaziland, Uganda), South Asia (Afghanistan and Pakistan), and the Caribbean (Haiti). Food insecurity leads to poverty, malnutrition, hunger, poor health, and high mortality rates.

Food insecurity inevitably harms public health. For example, acute and chronic malnutrition among children under two years of age in Bangladesh is a cause of delay in their development, affecting about $48.6 \%$ of the country's 20 million children. About onethird of teenage girls in Bangladesh suffer from anemia and micronutrient deficiencies [1]. Malnutrition due to lack of food has led to stunted growth in $50 \%$ of children under five in

\footnotetext{
*Corresponding author: antamoshkina@mail.ru
} 
India. In the Himalayan region, most rural residents do not have access to sufficient food in their diets and thus suffer from diseases associated with nutritional deficiencies [2].

Even economically prosperous countries of the world face problems associated with public health and food security. In particular, the USA suffers from overweight, including among children and schoolchildren, increased anxiety and aggression in children, depression, the development of chronic diseases [3]. Also, food insecurity negatively affects the US economy and health care system, as poor health conditions increase the incidence of sickness in the population and an increase in the number of days off work due to illness. Thus, labor productivity decreases, the quality of human capital deteriorates, the volume of use of medical services increases, and the overall burden on the healthcare system increases.

Food security of the country is an integral part of national security, which guarantees regular access of the population to high-quality and safe food for the consumer. Food serves as a basic indicator of a person's vital activity; insufficient, absent or low-quality food inevitably leads to negative consequences since a full and balanced diet largely determines the health and life expectancy of the population. The food supply of the population and the food security of the state must be sustainable, which will create conditions for the systematic replacement of imported food with products of Russian manufacturers, and provide the population with high-quality and safe food products.

\section{Materials and Methods}

\subsection{Assessment of food security based on fuzzy-multiple systems and models}

A feature of modeling and assessing the level of food security based on the requirements of the current Doctrine of Food Security [4] is the need to consider at least two levels - by spheres and individual indicators. Also, a significant number of particular indicators and incomplete certainty of the preferred levels make it difficult to use economic and mathematical models. In this regard, it becomes necessary to use fuzzy-multiple systems and models. Fuzzy logic systems are recommended to be used in cases where complex processes are studied that do not allow the construction of simple mathematical models, or if expert knowledge about an object or a process can be formulated only in the linguistic form $[5 ; 6 ; 7]$. The mathematical apparatus of fuzzy logic is used when the available quantitative and qualitative information is insufficient, or it is incomplete to obtain statistically significant conclusions with the required degree of reliability. This approach makes it possible to form a set of alternatives based on fuzzy estimates of their technical and economic indicators through expert ranking, or by solving the formulated problem of economic and mathematical optimization.

\subsection{Assessment of the food security sustainability based on factor analysis}

The theory of sustainable development allows us to consider various types of economic models of sustainability. Concerning the analysis of food security sustainability, it is advisable to use a multifactorial, dynamic model for assessing sustainability, which allows considering the influence of systematized groups of factors that form food security in the production (P), distribution (D), and consumption (C) of food products. Modeling of the assessment of the sustainability of food security based on factor analysis will identify new universal patterns in the system of food security of the state and establish the relationship between the factors that determine food security in the production, distribution, and 
consumption of food products. Besides, modern conditions dictate the need to consider the impact of import substitution (I) on food security.

\section{Results and Discussion}

The considered model and methodological approach to assessing the sustainability of food security suggests distinguishing four groups of food security sustainability factors characterizing the spheres of production (P), distribution (D), consumption (C), and import substitution (I) of food products (Table 1).

Table 1. Food security factors and indicators

\begin{tabular}{|c|c|l|}
\hline Factors & Indicators & \multicolumn{1}{|c|}{ Evaluation parameters, \% } \\
\hline \multirow{2}{*}{$\mathrm{P}$} & $\mathrm{p}_{1}$ & agricultural production indices \\
\cline { 2 - 3 } & $\mathrm{p}_{2}$ & level of food self-sufficiency \\
\hline \multirow{3}{*}{$\mathrm{d}$} & $\mathrm{d}_{1}$ & food price indices \\
\cline { 2 - 3 } & $\mathrm{d}_{2}$ & $\begin{array}{l}\text { real money income of the population, \% against the } \\
\text { previous year }\end{array}$ \\
\cline { 2 - 3 } & $\mathrm{d}_{3}$ & population with incomes below the subsistence level \\
\hline \multirow{3}{*}{$\mathrm{C}$} & $\mathrm{c}_{1}$ & $\begin{array}{l}\text { share of food expenses in the structure of consumer } \\
\text { expenditure }\end{array}$ \\
\cline { 2 - 3 } & $\mathrm{c}_{2}$ & $\begin{array}{l}\text { food consumption as a percentage of the rational } \\
\text { consumption rate }\end{array}$ \\
\hline \multirow{3}{*}{$\mathrm{I}$} & $\mathrm{i}_{1}$ & $\begin{array}{l}\text { production indices of the main types of import-substituting } \\
\text { food products }\end{array}$ \\
\cline { 2 - 3 } & $\mathrm{i}_{2}$ & $\begin{array}{l}\text { share of imports of certain food products in commodity } \\
\text { resources }\end{array}$ \\
\hline
\end{tabular}

To analyze the sustainability of Russia's food security at the macroeconomic level, an original methodological toolkit is proposed - the Food Security Sustainability Index $\left(I_{F S}\right)$. The food security sustainability index $\left(I_{F S}\right)$ is planned to be determined based on the weight $\left(w_{i}\right)$ of each block of food security sustainability factors:

$$
I_{F S}=\sum w_{i} f_{i}
$$

The Food Security Sustainability Index $\left(I_{F S}\right)$ calculation procedure includes three stages: the initial stage involves an analysis of groups of indicators for each of the factors under consideration (P; D; C ; I) that influence the formation of food security sustainability using various multidimensional assessment methods. Then, considering the obtained values of each block of food security sustainability factors, an integral assessment is formed for each of the food security sustainability factors - $\left(f_{p}, f_{d}, f_{c}, f_{i}\right)$. At the final stage, based on the proposed methodology, a complex indicator of the Food Security Sustainability Index $\left(I_{F S}\right)$ is calculated, based on the influence of three blocks of factors in the production (P), distribution (D), consumption (C), and import substitution (I) of food products. The established range of the stability index is within $0<I_{F S} \leq 1$.

Based on the study of food availability and accessibility and the assessment of food security vulnerabilities, food security can be classified into four types:

- very high level of food security;

- high level of food security;

- moderate food insecurity; and

- low food security [1].

Objectively limited financial resources of households restrict access to food, although hunger is empirical and can only be felt by the person who feels it. D. Lomeling and 
R. Wani, based on the concept of continuous food security, present an approach to identifying the levels of food security concerning households:

- food insecurity (households show no or minimal evidence of food insecurity);

- food insecurity without hunger (food insecurity is obvious, household members are concerned about the amount and quality of food, access to food);

- food insecurity with moderate hunger (food intake by adult family members is reduced to the level of regular hunger);

- food insecurity and acute hunger (adults in families with and without children significantly reduce food intake, to such an extent that all family members, including children, constantly feel hungry) [8].

Among the many factors that affect food security, the most significant are economic (unemployment, poverty, income and purchasing power, rising food prices), political (political instability in states and countries of the world, military and civil conflicts), and natural and climatic (extreme weather events, climate, droughts, alternative use of land resources).

In particular, a positive relationship has been established between political stability and food security. Food security in terms of the physical availability of food can be ensured in several ways: domestic agricultural production, organizing the population's access to food through an efficient marketing system (trade, transport infrastructure), purchasing imported food, or supplying food in the form of food aid. The factor of political instability in the state significantly reduces the effectiveness of each of the above methods of ensuring food security. Political instability, including, clearly demonstrates the relationship between socio-economic, agricultural policy, and state policy, which includes regulation of all sectors and spheres of the economy.

The organization of food production requires significant investments from agricultural producers: the cost of purchasing agricultural machinery, seeds, fertilizers, plant protection products, labor costs, and other types of costs. Agricultural activity is always associated with certain risks: for example, crop failure due to drought, plant and animal diseases. If the standard risks of agricultural production are amplified by political instability, this type of activity becomes economically impractical and there is no opportunity to attract investment and organize agricultural production in a politically unstable region or state. Low food production in turn leads to food insecurity.

The access of the population to food products through the organization of an effective food distribution system can also be largely limited by political instability, which will affect both the demand and the supply of food on the market. B. James Deaton and B. Lipk note that political instability has a particularly detrimental effect on the ability of the population, especially the poor, to earn income and thus buy food [9]. The functioning of trade and transport infrastructure can also be significantly complicated by factors of political instability. In the event of crop failure in the country, for example, due to drought, the lack of food in the domestic market could be compensated by trade between countries. However, the political instability in the country, as a rule, prevents from using this opportunity to purchase and supply food to the domestic market.

Climatic factors traditionally have a significant impact on food production and availability, and food security in general. Human-induced global warming can raise the risk of hunger, especially among the world's poor people. Further changes in climate and weather conditions presuppose the need to adapt agricultural technologies to the existing variability of climatic factors, this can become the basis of food security for the world's population. K. Fanjiru and Thomas J. Ngigi in their case study on assessing and monitoring the main drivers of declining food production and food security, show on the example of Kenya that a decrease in food production is associated with a decrease in precipitation [10]. 
Most countries in the world face the problem of declining agricultural land due to competition with their non-agricultural uses such as urban sprawl, the need to allocate part of the land for road infrastructure or mining [11]. All this can lead to a decrease in agricultural production and pose a real threat to food security. Even if a sufficient amount of food is produced in a country or its separate region, this does not mean that the entire population will be provided with food products. For example, in Bangladesh, despite significant progress in the production of food grains, the problem of food security is still urgent. Approximately about $49 \%$ of households are poor, and $23 \%$ are extremely poor and do not have the resources to purchase sufficient food and, therefore, remain below the poverty line [1]. Rice, wheat, legumes, milk, butter, meat, fish, potatoes, vegetables, sugar, and fruits make a fixed set of food products that meet the minimum nutritional requirements of 2,122 kcal per day per person. The extremely poor people typically consume less than the minimum calorie intake ( $1805 \mathrm{kcal} /$ day $)$, and any further reduction in food intake will certainly impair their health, physical ability, and performance.

\section{Conclusions}

Modeling of the assessment of the sustainability of food security based on factor analysis will identify new universal patterns in the system of food security and establish the relationship between the factors that determine food security in the production, distribution, consumption, and import substitution of food products. The theoretical significance of the problem of developing a methodology and procedure for calculating a complex multifactorial indicator - the food security sustainability index is associated with the need to monitor and assess the state of food security and predict food needs for the Russian population. The practical significance lies in the possibility of ranking Russian regions by types of sustainability to further propose adequate measures in regions with a low or minimum permissible level of sustainability when developing a food security sustainability strategy.

\section{Acknowledgments}

The article was prepared with the financial support of RFBR under the project 19-07-01132 "Creation of an intelligent system for assessment and forecasting of food security in the conditions of import substitution based on fuzzy cognitive approach".

\section{References}

1. M. Mohiuddin, M. Islam, M. Uddin, T. Poverty, Journal of Food Security, 4 (2016)

2. V. Sati, Journal of Food Security, 3 (2015)

3. R. Brasseur, A. Ozier, R. McBride, A. Powell, E. Ratliff, P. Yao and M. Calvin, Journal of Food Security, 3 (2015)

4. Food Security Doctrine of the Russian Federation the Presidential Decree from 30.01.2010, Rossiyskaya Gazeta 5100 (2010)

5. A. Rogachev, Asian Social Science 11 (2015)

6. Rogachev, E. Antamoshkina, IOP Conference Series: Earth and Environmental Science 403 (2019)

7. L.A. Ginis., G.V.Gorelova, A.E. Kolodenkova, International Journal of Economics and Financial, 6 (5) (2016) 
8. D. Lomeling, R. Wani, Journal of Food Security, 3 (2015)

9. B. Deaton, B. Lipka, Journal of Food Security, 3 (2015)

10. T. Ngigi, E. Kibunga, Journal of Food Security, 5 (2017)

11. T.M. Yarkova, A.G. Svetlakov, Economy of the region, 436 (2013) 